notified cases and completed so many questionnaires. Our thanks are also due to Mr. P. Samuel, lecturer in computer science, at the Welsh National School of Medicine, Cardiff.

\section{References}

1 West, K. M., Diabetes, 1960, 9, 379

2 Cooke, A. M., et al., British Medical fournal, 1966, 2, 674.

3 Tattersall, R. B., and Pyke, D. A., Lancet, 1972, 2, 1120.

${ }^{4}$ Medical Research Council, British Medical fournal, 1973, 1, 313.

${ }^{5}$ Gamble, D. R., Proceedings of a Workshop-Conference on the Genetics of Diabetes, Gottingen 1975. Berlin, Springer-Verlag, in press.

${ }^{6}$ Adams, S. F., Archives of Internal Medicine, 1926, 37, 861.

${ }^{7}$ Gamble, D. R., and Taylor, K. W., British Medical fournal, 1969, 3, 631.

${ }^{8}$ Gamble, D. R., Postgraduate Medical Fournal, 1974, 50, Suppl. 3, p. 538.

9 White, P., Diabetes in Childhood and Adolescence, p. 61. Philadelphia, Lea and Febiger, 1932.
10 Danowski, T. S., Diabetes Mellitus, with Emphasis on Children and Young Adults, p. 129. Baltimore, Williams and Wilkins, 1957.

11 Oakley, W. G., Pyke, D. A., and Taylor, K. W., Clinical Diabetes and its Biochemical Basis, p. 591. Oxford, Blackwell, 1968.

12 Cudworth, A. G., and Woodrow, J. C., Lancet, 1974, 2, 1153.

${ }^{13}$ Dingle, J. H., Badger, G. F., and Jordan, W. S., Illnoss in the Home, A Study of 2500 Illnesses in a Group of Cleveland Families, Cleveland, Ohio, Press of Western Reserve University, 1964.

14 Stewart, H. C., and Stevenson, S. S., Textbook of Pediatrics, ed. W. E. Nelson, 7th edn., p. 50. Philadelphia, Saunders, 1959.

15 Marshall, W. A., and Tanner, J. M., Archives of Diseases of Childhood, 1969, 44, 291.

${ }_{16}$ Marshall, W. A., and Tanner, J. M., Archives of Disease in Childhood, 1970, 45, 13.

17 Spicer, C. C., Fournal of Hygiene, 1961, 59, 143.

${ }^{18}$ Lennette, E. H., Magoffin, R. L., and Khoug, E. G., fournal of the American Medical Association, 1962, 179, 687.

19 Office of Population Censuses and Surveys, Census 1971, County Report and Census 1971, Scotland, Population Tables. London, H.M.S.O., 1971.

\title{
Social Medicine
}

\section{Community Participation in Primary Health Care}

\author{
P. M. M. PRITCHARD
}

British Medical fournal, 1975, 3, 583-584

\section{Summary}

A two and a half year's experience of a community participation group has shown that this can have a valuable role in suggesting practicable improvements in a group practice. Topics discussed by the group (which is composed of one representative from every known organization in the area) have included problems of receptionists; the role of the individual ancillary worker; and teaching in general practice. The high attendance rate at the group's meetings testifies to the community's interest in primary health care services.

\section{Introduction}

The setting up of community health councils (C.H.C.s) in the reorganized National Health Service has aroused interest in securing the community's involvement in health services. Many of the problems encountered in formulating and implementing the proposals for C.H.C.s were experienced by the general practitioners and other health professionals working from the Berinsfield Health Centre when a community participation group (C.P.G.) was established in 1972.

C.H.C.s are an important innovation in the N.H.S. because for the first time they give the population being served by local health services the right and obligation to comment on all those services. The aim of the councils is to enable a continuing

The Health Centre, Berinsfield, Oxford OX9 8NE

P. M. M. PRITCHARD, M.B., M.R.c.G.P., General Practitioner dialogue to go on between those providing the services and those for whom the services are being provided, and a crucial issue is the "representativeness" of their membership. If the membership of C.H.C.s is felt to exclude significant interest groups their aim of giving a total community view on all services will not be fulfilled.

In establishing the C.P.G. we were confronted with a similar problem. If we were to get representative views on the primary health care services how were we to constitute the C.P.G. ? Much has been published on investigations undertaken to get patients' views on specific issues in primary health care, ${ }^{12}$ but there is little evidence of successful attempts to secure continuing comment and discussion between the providers of primary health care and their public. If our patients were to take seriously our invitation to comment on our services we had to ensure that the C.P.G. was the sort of body through which they were willing to make their views known. This and other issues have continued to concern us during the two and a half years of the C.P.G.'s existence. This paper describes the C.P.G. and the ways in which we have tackled some of these issues.

\section{Background}

The practice serves a population of 6800 , half of whom live in Berinsfield, where the health centre is situated. Berinsfield is a "new village,"3 which was established in 1958 . The other half of the population is in small villages within a radius of five miles of the health centre.

On moving to the health centre in January 1970 the pattern of practice started to change, with emphasis on team work involving treatment room sisters, health visitors, district nurses, and social workers. More patients were able to visit the centre, with the help of voluntary car services, and fewer home visits were undertaken. Laboratory services were used more, and much effort was expended on preventive work and screening. Participative management was encouraged by regular staff meetings. In 1972 the partners felt the need to include patients in this participation, and a group was set up which first met on 30 November 1972. 


\section{Method}

The group was constituted by asking every known organization in the area served by the practice to send a representative. As a result representatives came from each parish council, local women's institutes, old people's clubs, voluntary car services, youth organizations, etc. The turnout was nearly $100 \%$. New organizations have been included as they are formed or we learn of them-for example, single-parent families.

Initially one of the general practitioners took the chair; later one of the representatives was elected as chairman and this arrangement has continued. Professionally qualified staff-that is, general practitioners, treatment room sisters, health visitors, district nurses, and social workers-attend the meetings.

We thought that if we confined membership to representatives of existing organizations rather than encourage volunteers we would get views from a wider range of patients, some of whom would otherwise be less likely to complain or make suggestions-for example, the elderly. Patients are generally reluctant to complain ${ }^{4}$ and might be more likely to do so when representing an anonymous complainant. We also hoped that a dialogue would be established so that any ideas or questions on which we might like patients' views could reach a larger number of people.

The group has met about every three months, and attendance has been good.

\section{Results}

Members tended to be reticent at first, but became more articulate in suggesting improvements in services, most of which have been implemented-for example, chiropody service with transport for the elderly and a shorter wait for the sister and dispensary. Discussion of topics like whether to bring a feverish child to the health centre or request a home visit resulted in a better understanding of attitudes and anxieties. Health workers were reminded of problems of particular groups, such as the elderly, single-parent families, and those without cars or baby sitters. The community was reminded of the part it could play in caring for the elderly living alone. "Help" cards for this group have been distributed and callers such as milkmen and paper boys told what to do if they see one.

Many members were not clear about the role of various members of the team such as health visitors, social workers, and treatment room sisters. These roles and ways of direct access were explained. The extent to which individuals should be responsible for their own health and self-treatment was also discussed. In response to a suggestion a booklet on "hints on keeping well" has been written and distributed. The pros and cons of various screening procedures have been discussed and help enlisted in publicizing them and designing questionnaires.

Members were helped to gain insight into the mechanics of providing medical care, and some of the difficulties were outlined. For example, staffing difficulties at weekends and evenings were explained, and the need for limited non-urgent consulting time in "unsocial hours" was discussed. The group agreed that a Saturday morning session was not needed on a bank holiday weekend. The group also agreed to a trial period without a treatment room sister on Saturday mornings. The difficulties of receptionists in trying to fit everyone in were explained, as was the doctors' preference for morning consultations to allow specimens to be transported to the laboratory. Emergency calls during surgery hours and the dilemma of whether to call a doctor or an ambulance in a serious emergency were discussed.

Financial constraints in providing comprehensive health care were understood and accepted.

The group's opinion was sought on the acceptability of trainee general practitioners and students in the practice. The conclusions were that trainees were welcome and that a woman was preferred (the three partners are all men). This has been implemented. The group's views were also sought on the taping (audio or video) of live consultations, with the patient's permission, for the purpose of teaching trainees; the group was totally opposed to the use of these methods, as it was thought that this would harm the doctor-patient relationship. Medical students were acceptable if the patient was warned by means of a typed notice giving the name and sex of the student, and had the option of seeing the doctor alone. Health visitor students would be accepted at child health clinics. Social work students would be accepted only in company with a social worker and not in the surgery.

There were interactions within the group-for example, the Women's Institute representative from one village discovered that hers was the only village without a surgery car service, so one was promptly organized. Topics raised at meetings were further discussed in the member organizations, and local groups were asked for suggestions and crimplaints before the C.P.G. meetings.

\section{The Future}

Other practitioners, particularly those in process of moving to a new health centre, have shown interest in our group. We hope that other groups will be formed, and that a nominee of these groups would be considered suitable to serve on the C.H.C. of the reorganized N.H.S. Our local C.H.C. has shown great interest in this development, and one of its members who is particularly concerned with community services attended the last meeting of the group, and is willing to attend future meetings.

\section{Conclusion}

Our experience has shown that it is possible to engage a community's interest in the primary health care services being provided for it; a constant high level of attendance at C.P.G. meetings and the range of issues discussed are indicators of that. The effectiveness with which representatives feed back information to their groups and the responsiveness of the membership of the C.P.G. to changes of balance of interest in the community are issues that have to be tackled if the C.P.G. is to continue to develop. If it succeeds not only will it give us the opportunity to tailor our services to meet the needs of the community better but it should also make health a matter of concern to the community regardless of whether or not individual members are personally using our services. Prevention of illhealth is likely to receive greater emphasis in the reorganized N.H.S. If bodies like the C.P.G. in primary health care and the C.H.C. in health services generally can, among other things, educate patients and staff to be more aware of health needs they will be well worth while.

I thank Miss Heather Tolliday, research fellow, health services organization research unit, Brunel University, for considerable help in the preparation of this paper.

\section{References}

${ }^{1}$ Kaim-Caudle, P. R., and Marsh, G. N., British Medical Fournal, 1975, 1, 262.

${ }^{2}$ Millar, D. G., fournal of the Royal College of General Practitioners, 1972, $22,866$.

${ }^{3}$ Morris, R. N., and Mogey, J., The Sociology of Housing: Studies at Berinsfield. London, Routledge and Kegan Paul, 1965.

${ }^{4}$ Cartwright, A., Patients and Their Doctors. London, Routledge and Kegan Paul, 1967. 